\title{
Conventional Sugarcane Breeding in South Africa: Progress and Future Prospects
}

\author{
Marvellous Zhou ${ }^{1,2}$ \\ ${ }^{1}$ South African Sugarcane Research Institute, Mt Edgecombe, South Africa; ${ }^{2}$ University of the Free State, Bloemfontein, South Africa. \\ Email: Marvellous.Zhou@sugar.org.za
}

Received November $13^{\text {th }}, 2012$; revised December $11^{\text {th }}, 2012$; accepted December $17^{\text {th }}, 2012$

\begin{abstract}
Initial sugarcane production in South Africa relied on imported varieties. When imported varieties succumbed to diseases, the industry established the South African Research Institute (SASRI) with the mandate to develop sugarcane varieties. The popular and highly successful varieties, $\mathrm{NCo} 310$ and $\mathrm{NCo} 376$ were selected from crosses imported from India. NCo310 and NCo376 were grown successfully in several countries across the world where they produced high yield and ratooning ability. Later, crossing was established at SASRI based on flowers initiated in the glasshouse and photoperiod house under controlled temperature and photoperiod conditions. A five stage program is currently being implemented in the variety development process. More than 60 varieties have been released from the breeding programs. Other achievements include development of germplasm that is currently being used to enhance sugar cane variety development in South Africa. Currently, high realised selection gains are evident in most of the advanced selection populations. The released varieties show genetic gains over time. Efforts to enhance the breeding program include introgression, family evaluation, selection models and use of molecular markers.
\end{abstract}

Keywords: Saccharum; Realised Gains; Family Selection; NCo310; NCo376

\section{Introduction}

The first sugar produced in South Africa in 1852 was derived from varieties of noble cane (Saccharum officeinarum sp.). Initially, South Africa was dependent on regular imports of new varieties and over time these varieties became susceptible to local diseases such as smut and mosaic [1]. Import of the variety Uba (S. sinensis) in the 1880s gave growers a respite, because Uba was resistant to mosaic. It also ratooned better than previous varieties, and each stool produced many stalks. Although Uba was pleasing to the growers, the millers did not like it because it was high in fiber and low in sucrose content leading to poor sugar recovering at processing. All growers were nevertheless urged by government to plant Uba to reduce sugarcane diseases. This strategy proved less than ideal around 1915 when Uba was found to be susceptible to streak disease, leaving the sugar industry in a crisis with no new varieties available to replace Uba. In 1925, the South African Sugarcane Research Institute (SASRI) was established at Mount Edgecombe, Durban, South Africa with the major objective of importing, testing and releasing better varieties. The majority of imported varieties were not adapted to local conditions and often succumbed to pests and diseases [2]. The failure of the majority of imported varieties led to the initiation of the SASRI breeding programs. The newly appointed researchers at the Experiment Station tried making crosses, but no fertile seed was obtained [3]. Later the Experiment Station imported true seed from several countries including India [4].

In 1945, Dr Peter Brett discovered that the absence of viable seed in crosses was caused by pollen infertility due to low temperatures during the flowering period. Sugarcane flower emergence in South Africa occurs in winter when temperatures often drop below $20^{\circ} \mathrm{C}$ thereby causing pollen sterility. Pollen infertility was overcome by keeping sugarcane flowers under temperatures above $20^{\circ} \mathrm{C}[3,5]$ in heated glasshouses. Breeding progress at SASRI was limited by variable flowering in parent genotypes. Further experiments developed procedures for inducing flowering by exposing the sugar cane plants to the day-lengths that occur in tropical countries where flowering is profuse [3]. In 1966 and 1971, SASRI constructed a glasshouse and photoperiod house, respecttively. Both facilities have controlled heating and lighting.

\section{0s to Mid-1990s}

The structure of the breeding programs remained largely unchanged from the early 1970s until the mid-1990s. Crosses were made at Mt Edgecombe, and seedlings 
were sent to 6 locations (Table 1) to undergo a five-stage selection programme. The different locations were established to develop varieties adapted to the different growing conditions that prevailed in the agro-ecological regions where sugarcane is grown in South Africa. In South Africa, differences in agro-climatic zones results in 3 main zones, viz. Irrigated, coastal and high altitude (Midlands), and three harvest cycles, viz. 12 months, 16 18 months and 24 months, respectively. Genotype by environment interaction for optimum harvest age is large and determines the structure of the breeding programs. In addition, pest and disease risk differs across the Industry zones. For example, smut is prevalent in the coastal and irrigated regions, eldana borer (Eldana saccharina) is endemic in coastal areas while mosaic and brown rust dominate the Midlands region.

In 1993, an internal workshop reviewed the SASRI breeding programs [6-8] after the loss of the Central Field Research Station (CFS) site to urbanisation, the highly variable soils on some research stations giving unreliable selection data, over-emphasis of breeding resource on the coastal belt, the need to capture soil types representative of the major growing areas and underemphasis of breeding resources in the Midlands area which had increased sugarcane production. The dry-land selection programme was restructured by replacing all existing selection sites with new sites better reflecting the major soil and agroclimatic zones of the South African sugar industry. The size of the SASRI programs was increased from 160,000 to 250,000 seedlings per annum (Table 2).

\section{Breeding and Selection Process}

\subsection{Parent Selection}

The breeding programs cycle starts with parent selection. Each year, the selected parents are planted in the glasshouse and photoperiod house to produce flowers for crossing. Parent varieties for each regional breeding program are selected based on high cane yield, high sucrose content, high sucrose yield, desirable agronomic traits such as good ratooning ability, freedom from diseases and resistance to eldana borer. Imported genotypes and wild germplasm are included as parents to widen the ge-

Table 1. Original selection sites used in the SASRI breeding programs.

\begin{tabular}{cccc}
\hline Selection site & $\begin{array}{c}\text { Region } \\
\text { (Age months) }\end{array}$ & $\begin{array}{c}\text { Number of } \\
\text { seedlings }\end{array}$ & $\begin{array}{c}\text { Number of } \\
\text { Single Lines }\end{array}$ \\
\hline Pongola & Irrigated North (12) & 50,000 & 4000 \\
Mtunzini & Coast (12) & 25,000 & 2000 \\
Shaka's Kraal & Coast (12) & 25,000 & 2000 \\
C.F.S & Coast (18) & 25,000 & 2000 \\
Mt Edgecombe & Coast (12) & 25,000 & 2000 \\
Holly Bros. & Midlands (24) & 9000 & 700 \\
\hline
\end{tabular}

Table 2. Current location of Research Farms where selection is conducted.

\begin{tabular}{|c|c|c|c|}
\hline $\begin{array}{l}\text { Research } \\
\text { Farm (code) }\end{array}$ & $\begin{array}{c}\text { Region } \\
\text { (Age, months) }\end{array}$ & $\begin{array}{l}\text { Number of } \\
\text { seedlings }\end{array}$ & $\begin{array}{l}\text { Number } \\
\text { of lines }\end{array}$ \\
\hline Pongola (F) & Irrigated North (12) & 50,000 & 4000 \\
\hline Empangeni (T) & Coastal high potential (12) & 50,000 & 4000 \\
\hline Gingindlovu (U) & Coastal avg. potential (12) & 25,000 & 2000 \\
\hline Gingindlovu (G) & Coastal avg. potential (18) & 25,000 & 2000 \\
\hline Kearsney (K) & Hinterland (16 - 18) & 50,000 & 4000 \\
\hline Bruyns Hill (B) & Midlands (24) & 25,000 & 2000 \\
\hline Glenside (S) & Midlands (24) & 25,000 & 2000 \\
\hline
\end{tabular}

netic base of the sugarcane breeding populations, and provide novel sources of disease resistance and other important traits. Species of wild germplasm used include the vigorous, low sucrose $S$. spontaneum and the poorgrowing, but high sucrose S. officinarum. Special crosses are also utilised to develop novel germplasm for use as parents in the future. The glasshouse and photoperiod facilities have space to plant 50 parent varieties for each breeding program, plus another 50 for special crosses such as for eldana resistance and introgression.

\subsection{Flower Initiation and Crossing}

There are five flowering treatments in the photoperiod house and three in the glasshouse. Each genotype is allocated to a particular photoperiod treatment and that determines its approximate flowering date. The photoperiod treatment also determines whether the genotype would be classified as male or female parent. A genotype is categorized as male or female based on the amount of viable pollen produced. Genotypes that produce large quantities of viable pollen ( $>30 \%)$ are classified as males, otherwise they will be females. Parent genotypes are planted in September of each year and replicated across flowering treatments. Flowering treatments commence in February. The temperature is kept above $20^{\circ} \mathrm{C}$ to ensure pollen fertility. The day-lengths are artificially maintained at 12.5 hours by artificial lighting. The photoperiod house provides greater control of day-length and is used to treat shy-flowering varieties, and to increase the number of flowers with fertile pollen (males) while the glasshouse is used to generate the majority of the female parents. Flowers emerge between 90 to 110 days after photoperiod treatment. The number of stalks producing flowers varies between $50 \%$ and $70 \%$, and depends on seasons.

When the first florets of a flower open, anthers are collected and stained with an iodine solution. Cross combinations depend on the breeders' objectives and available flowers. During crossing, the minimum temperature is kept above $20^{\circ} \mathrm{C}$, and humidity levels are maintained above $70 \%$ to ensure good pollen viability, pollen survival and seed set. After 14 days from crossing, 
when shedding of pollen ceases, the males are discarded and the female flower is ripened. At SASRI, flowering and crossing take place from May to August. Approximately 1500 crosses are made every year. An average of 350 seeds per flower is produced. The matured flowers are harvested and dried when the topmost part of the flower begins to fluff up, a sign that the seed is mature. The fuzz and the seed it contains are dried for 24 hours at $30^{\circ} \mathrm{C}$. A sample of seed is taken for a germination test and the remaining seed is placed in a plastic sachet and sealed, each cross separately. The seed is stored in a cold room at $-20^{\circ} \mathrm{C}$ until required. The seed remains viable for 10 years.

\subsection{Selection Program}

The main objective of the programs is to select varieties suited to the major agro-climatic regions of South Africa. To achieve this objective, selection is carried out at six research stations (Table 2). The first four stages of the selection programme are established at the research stations. Stage 5 genotypes are planted across research stations and on-farm trials to evaluate for genotype by environment interaction. It takes between 11 (irrigated program) and 20 (Midlands) years from the seedling stage to the release of a new commercial sugar cane variety.

\subsubsection{Stage 1: Seedlings in Terraces}

The selection programs starts with seedlings raised in the glasshouse. About 250,000 seedlings are raised from true seed each year (Table 2). Crosses planted are made up of proven crosses (that are known to produce high yield progenies) and test crosses (derived from unknown parents). Each cross is sown in a separate box by spreading the fuzz evenly over the surface of a mixture of peat moss and river sand. The fuzz is lightly covered with peat moss and watered, then placed in a heated glasshouse at $30^{\circ} \mathrm{C}$. Germination occurs within three days. Five days after sowing the seedlings are counted, and moved outside the glasshouse for steadily lengthening periods until they are hardened off. When the seedlings are $3-5 \mathrm{~cm}$ tall, they are transplanted to airbricks in a nursery. The seedlings in a cross are divided into three groups and each group is planted in a replication. The seedlings are left to grow for seven to nine months. The best $66 \%$ of the seedlings are advanced to the next stage, where the miniature stalks (setts) of $1 \mathrm{~m}$ length are planted in the field.

\subsubsection{Stage 2: Mini-Lines}

The setts from stage 1 are planted individually as one meter plots, one meter apart in the row. The row widths in all trials range from 1.0 to $1.4 \mathrm{~m}$, depending on the research station. Every third row is skipped to allow sufficient room for the mini-lines to be examined for major diseases, as well as for visual appraisal during selection. Selection at the Mini-lines stage is based on visual assessment, freedom from disease and the family values for yield, sucrose content, diseases and pests. The family data is obtained by determining the sucrose content [9] in a sample of one stalk from each of a sample of 20 plots. Family cane yield is estimated from yield components (number of stalks, stalk height, stalk diameter) from a sample of 20 to 50 plots. Family disease scores and eldana borer damage data is also analysed. Approximately $11 \%$ of Mini-lines are selected.

\subsubsection{Stage 3: Single Lines}

Selected genotypes from stage 2 are planted in $8 \mathrm{~m}$ row plots. It is at this stage that each clone receives a unique number, for example 98F2225: the year the line was planted (98 for 1998), the site ( $\mathrm{F}$ for irrigated) and its location (2225 line number 2225) in the trial. Periodic disease inspections are carried out. At harvest, 12-stalks are randomly sampled per plot and used to determine sucrose content in the laboratory [9]. Cane yield is estimated from number of stalks, stalk height and stalk diameter. Due to the small plot size, the large trial size and lack of replication, field variability is large. The data is therefore adjusted for spatial trends. Selections to Stage 4 are based on yield estimates, disease and pest data and visual evaluation of the genotypes in the field.

\subsubsection{Stage 4: Observation Trial}

Genotypes selected to Stage 4 are planted to two rows by $8 \mathrm{~m}$ plots and three replications. The trial plots are harvested and sampled for sucrose content in plant and first ratoon crops. At harvest, all the millable stalks in the plot are manually cut and weighed. Twelve stalks are randomly chosen and analysed for sucrose content at the laboratory [9]. In the irrigated breeding program where smut is a problem, the genotypes are planted into preliminary smut inoculation trials. In the coastal breeding programs, a 20 -stalk sample per plot is used to estimate eldana borer damage at time of harvest. Selections to Stage 5 are based on the combined analysis of the data collected from the plant and first ratoon crops.

\subsubsection{Stage 5: Advanced Variety Trial}

Advanced variety trials provide final evaluation before a genotype is recommended for commercial planting. Genotypes that produced significantly $(\mathrm{P}<0.05)$ higher yield than the control genotypes in Stage 4 are include in advanced variety trials. The trials are established at 6 locations and across research stations to evaluate for genotype by environment interaction and harvested in the plant, first, second and third ratoon crops to evaluate for ratooning ability. Further disease and pest screening trials are established at this stage to determine resistance 
levels for smut, mosaic and eldana borer. Combined data analysis is used to recommend varieties for release by determining the areas of adaptability and ratooning ability. Genotypes recommended for release are expected to produce significantly $(\mathrm{P}<0.05)$ higher sugar yield than control genotypes and possess higher levels of resistance to diseases and pests prevalent in the agro-ecological region recommended for release. Details of the progresssion of selection are shown in Table 3.

\section{Progress}

From the days of importing crosses from India up to date, significant progress has been made in the variety development programs. Associated with the elite varieties released for commercial production, a lot of progress has been made in germplasm development, parent evaluation, crossing techniques and selection procedures. Greater understanding of genotype by environment interaction has resulted in efficient variety testing and the development of testing sites and procedures. The significant genetic gains among breeding populations have led to genetic gains among released genotypes.

\subsection{Germplasm Development}

To date, 1800 germplasm lines have been developed (Table 4) that possess desirable trait values ranging from high cane yield, high sucrose content, disease and pest resistance. A comprehensive variety collection made up of 837 varieties released by SASRI and those imported from other countries also includes the legendary PoJ varieties which make the basis of most modern sugarcane hybrids. In addition to the collection of hybrids, wild sugarcane relatives including 23 Saccharum officinarum, 37 S. spontaneum, 9 S. robustum, 13 Erianthus and 76 F1 and $\mathrm{BC} 1$ genotypes make up the germplasm collection. The Saccharum collection was imported from other countries because sugarcane is not indigenous to South Africa.

\subsection{Realised Selection Gains over Time}

The realised selection gains over time were assessed using advanced variety trials data because it represents the final and pre-release stage where genotypes are likely to be released. Any gains reflected at this stage would ultimately lead to higher potential gains for genotypes being released for commercial planting. These trials are planted at several locations and therefore the data would also be more representative of their true genetic potential across the target areas for release. The trait evaluated was sugar yield because it represents the product the farmers are paid for their crops. The data for sugar yield $(t / h a)$ were transformed to reduce the effect of year to year seasonal variation. To transform the data, all the values were divided by the control (NCo376) that is used across all programs to convert to percentages. It is the percentages that were used in this analysis.

For the irrigated region, the data covered 13 cycles of plant breeding and selection. The populations were derived from crosses done from 1990 to 2002 and advanced variety trials were harvested from 1998 to 2011. The trials were established at four locations, two trials (Pongola research station and Komati research station) were planted and harvested in the early season and three trials (Pongola research station, Pongola off-station, Mhlati off-station in Mpumalanga) were planted and harvested in the late season. The trials were harvested at 12 month crop age for four crops (plant, first, second, third ratoon). The average genotype mean for each series was generated using least square means from a combined analysis of all the data from all locations and across all the crops using mixed models of the Statistical Analysis System [10]. The genotype means (\%control) (y-axis) were plotted against the series year (x-axis) (Figure 1). In order to determine the significance of the trends, a regression analysis was performed using the regression procedure of SAS where the genotype means (\%control) was the re-

Table 3. Details of the progression of selection in a breeding program.

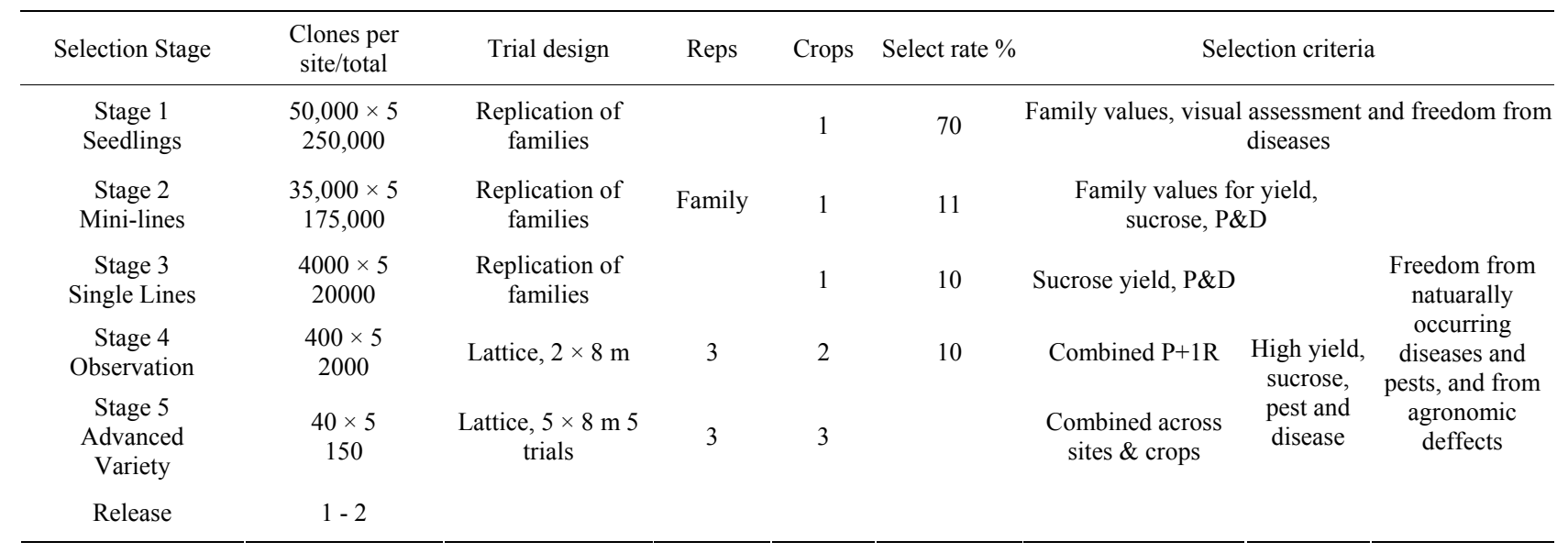


Table 4. SASRI germplasm collection.

\begin{tabular}{cc}
\hline Species/collection & Number of genotypes \\
\hline Germplasm developed by SASRI & 1800 \\
Variety collection & 837 \\
Saccharum officinarum & 23 \\
Saccharum spontaneum & 37 \\
Saccharum robustum & 9 \\
Erianthus & 13 \\
F1, BC1 & 76 \\
\hline
\end{tabular}

sponse variable and the series was the predictor variable.

For the coastal short cycle, the data covered 12 cycles of plant breeding and selection. The populations were derived from crosses done from 1990 to 2002 and advanced variety trials were harvested from 1998 to 2011. The data were derived from five trials established at four locations. Four trials were planted and harvested early season at Gingindlovu research station, Empangeni research station, Gingindlovu off-station and Empangeni off-station while one trial was planted and harvested late season at Empangeni research station. The trials were harvested at 12 month crop age in the plant, first and second ratoon crops.

The coastal long cycle and hinterland data was derived from 11 cycles. The populations were derived from crosses done from 1990 to 2002 and advanced variety trials were harvested from 1997 to 2011. The data were derived from five trials established at five locations. Three trials were planted and harvested, one at Gingindlovu research station, two off-station trials near the Gingindlovu research station. Two trials were planted and harvested at Kearsney, one on-station and the other off-station. The trials were harvested at 18 month cropage in the plant, first and second ratoon crops.

The Midlands region data was derived from 11 cycles of trials. The populations were derived from crosses done from 1990 to 2002 and advanced variety trials were harvested from 1998 to 2011. The data for the Midlands programs was from six trials established at six locations, three each (one on-station and two off-station) for the sandy (Glenside research station) and humic (Bryuns Hill research station) soils. The trials were harvested at 24 month crop-age in the plant, first and second ratoon crops.

There were highly significant $1.09 \%(\mathrm{r}=38 \%, \mathrm{P}<$ $0.001)$ gains per cycle for sugar yield in the irrigated region (Figure 2). The irrigated program has produced the largest number of released and promising varieties in recent years. The coastal short cycle programs produced a significant $-0.50 \%$ negative gain $(\mathrm{r}=14 \%, \mathrm{P}<0.005)$ per cycle. Very few promising varieties have emerged from this programme since inception indicating potential deficiencies with its gene pool. There was a $1.69 \%$ and significant $(\mathrm{r}=41 \%, \mathrm{P}<0.001)$ gains per cycle for the coastal long cycle programs. The coastal long cycle breeding programs have shown great improvement in populations in later series and more promising varieties are emerging from the advanced variety trials. The Midlands produced the highest and significant $2.57 \%(\mathrm{r}=$ $54 \%, \mathrm{P}<0.001)$ gain per cycle. In recent years, exceptionally high yield cultivars such as N31, N48, N50 and N52 have been released while several promising genotypes have emerged.

\subsection{Released Varieties}

To date, more than 60 varieties have been released from the SASRI breeding programs. The earliest successful varieties released were selected from seed of crosses imported from India in 1938. The cross Co421 × Co312 made at the Sugarcane Breeding Institute in Coimbatore, India was the most productive. The cross was made by the breeder Dr TS Venkatraman and seed imported to KwaZulu Natal in two batches, one batch in 1938 and the other in 1944 [11]. The 1938 batch produced variety NCo310 which was released in 1945 while NCo376 was released in 1955 from the 1944 batch [4]. The sibling cultivars NCo310 and NCo376 became two of the most widely grown cultivars in South Africa and in many other parts of the world for a significant part of the $20^{\text {th }}$ century, a testimony to their wide adaptability and superior yield.

NCo310 was very popular with growers because it produced high cane yield and high sucrose content throughout the milling season. Ten years after release, NCo310 produced more than $50 \%$ of the total sugar produced in South Africa [12]. The decline in the area planted to NCo310 occurred 20 years later due to its high susceptibility to smut and the rapid adoption of NCo376. NCo310 was exported to several countries (Table 5) creating a world-wide sensation. It remained the major cultivar in Egypt, Morocco, Sudan, Somalia, Kenya, Zambia, Malawi, Mozambique, Zimbabwe and Swaziland until it was replaced by NCo376. NCo310 experienced the fastest adoption in Taiwan [13]. The cultivar made such an impact that NCo310 sugarcane memorial was erected and exists to date. The cultivar was received in Taiwan in 1947 where extensive testing showed that it produced significantly higher yield than controls. By 1952, 39,869 hectares were planted with NCo310, one of the fastest variety adoptions. It was later replaced in Taiwan by its progenies (F146, F160, F164 and F167) in 1967.

NCo310 was planted in Australia where it was a major cultivar from 1966 to 1986 [11]. At its peak, 68\% of the area under cane in Australia was NCo310. In 1954 NCo310 was released in Louisiana, USA where the area planted reached $25 \%$ in 1961 [14]. It was popular in Louisiana because of its tolerance to freezing damage, 

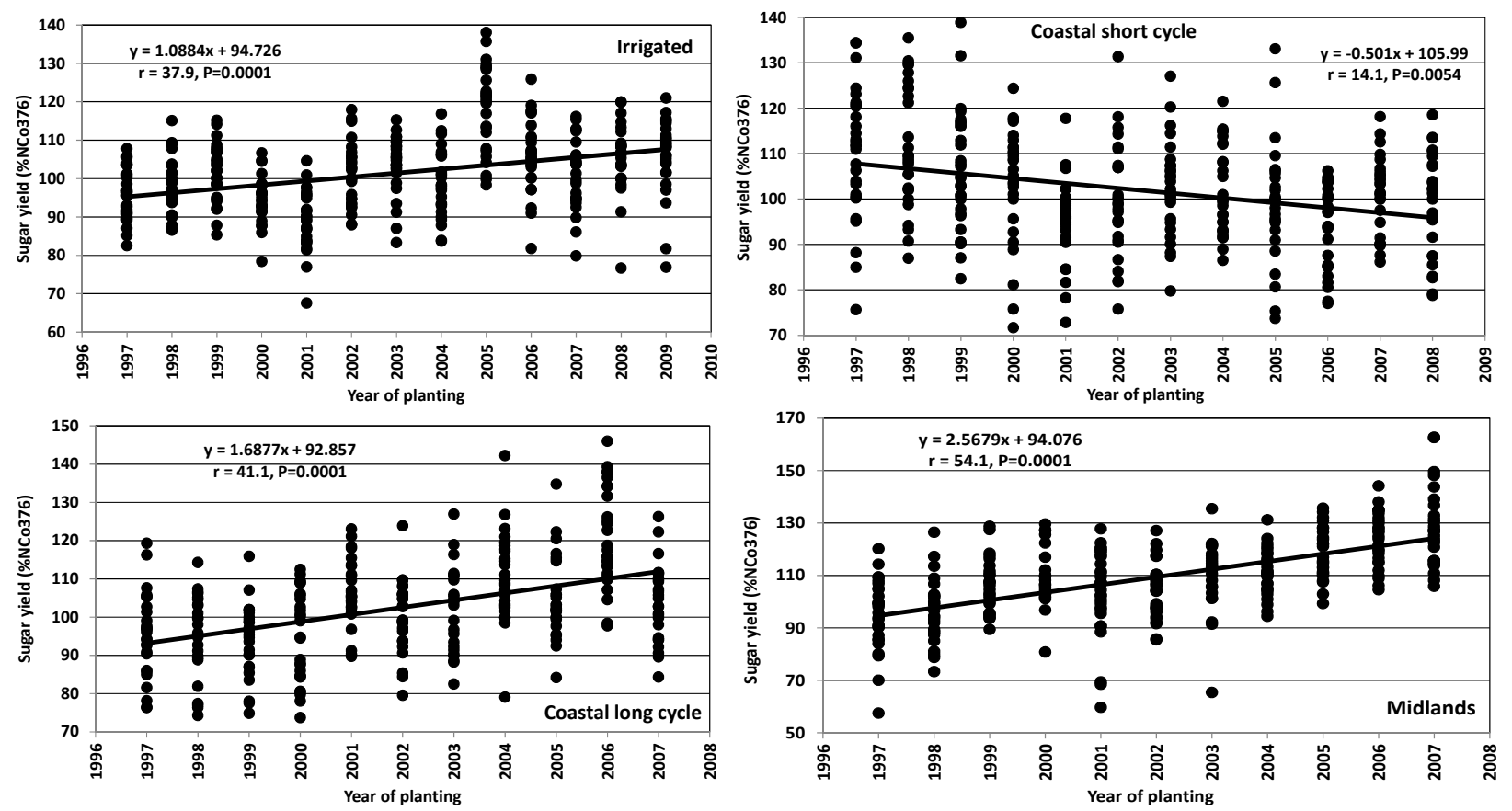

Figure 1. Gains over time for sugar yield (t/ha) for SASRI breeding programs.

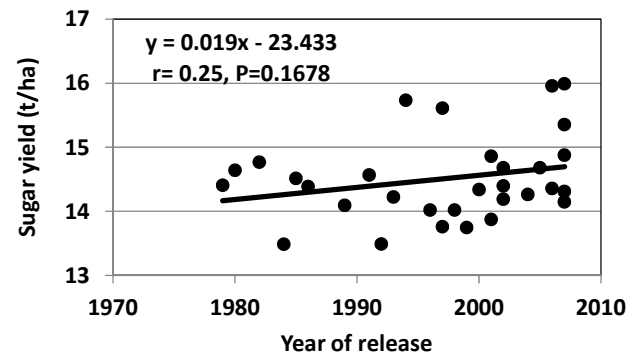

Figure 2. Performance of SASRI released varieties over time.

Table 5. List of countries and estates that imported NCo310 from 1945 to 1955 [11].

\begin{tabular}{cc}
\hline Year & Countries \\
\hline 1945 & USA, Argentina \\
1946 & Zimbabwe, Mozambique, Malawi, Australia (Brisbane) \\
1947 & Cuba, Taiwan, Tanzania, Philippines, India (Coimbatore), \\
& Brazil \\
1948 & Australia (Queensland), Coimbatore and Gopalpur (India), \\
& Turkey, Somalia, Madagascar \\
1949 & Turkey, Paris, Uruguay, Belgian Congo \\
1950 & Madagascar, Pakistan, Guadeloupe, Cuba, Israel, Angola, \\
1951 & Enya \\
1952 & Sudan, Malawi, Tanzania, Kenya, Ethiopia, Swaziland \\
1953 & Congo Brazzaville, Mexico \\
1954 & Mexico, Gold Coast (West Africa), Spain, Argentina \\
1955 & Libya, Tunisia, Belgian Congo, Zimbabwe \\
\hline
\end{tabular}

ease of mechanical harvesting and good ratooning ability. It was phased out in the 1970's due to susceptibility to smut. In the Rio Grande Valley of Texas, the cultivar at the height of its popularity reached $65 \%$ of the area [15]. It remains an important late season cultivar in Texas where it has produced high cane yields, is resistant to borers, has good ratooning characteristics and is cold tolerant. In Japan, NCo310 was a major cultivar between 1960 to 1992 where up to $80 \%$ of the area under cane was NCo310 [11].

Cultivar NCo376 was released in 1955 and was described as producing high yields in all trials, across different soil types and in regions ranging from hot and wet coastal areas to the cool midlands and irrigated regions in South Africa [4]. This cultivar produced higher cane yield than $\mathrm{NCo} 310$ and lower sucrose content. NCo376 went on to dominate the Southern Africa sugar industries for several decades [16]. It remained the most widely planted cultivar in South Africa from 1969 to 1991 and one of the major cultivars until 1995, when it was surpassed by one of its progeny, N12. It was widely grown in Swaziland, Mozambique, Malawi, Kenya, Tanzania, Zambia and Zimbabwe [16] and was planted to more than $90 \%$ of the area in those countries for more than 30 years. NCo376 has been touted as a scientific model genotype for breeders and is used as a control in SASRI plant breeding trials [4]. In addition, its traits include the best combination of yield components (number of stalks, stalk height and stalk diameter) and compensates well under adverse growing conditions. It is known to possess excellent ratooning ability and is on record having pro- 
duced high yields in crops over 30 ratoon cycles in Swaziland (Bernard Shongwe, Swaziland Sugar Association, personal communication) and Zimbabwe (Obert Mhondiwa, Tongaat Hulletts Zimbabwe, personal communication).

Both $\mathrm{NCo} 310$ and $\mathrm{NCo} 376$ were also successful as parents. In 1945, NCo310 was crossed with Co301, which resulted in the release of $\mathrm{N} 10$ and $\mathrm{N} 55 / 805$ in South Africa. A cross between NCo310 and Co331 in Japan produced cultivar NiN2. NiN2 was imported by SASRI and used as parent where one of its offspring gave rise to the popular coastal cultivar N27. In Taiwan, NCo310 as a parent produced major cultivars F146 and F160 and is part of the pedigree of other cultivars [13]. In Australia, NCo310 as a parent produced more than 13 "Q" cultivars. NCo310 was used as a parent in other countries including Mauritius, Reunion and Cuba [17]. NCo376 was crossed with Co331 and produced N55/77 [4]. It was crossed further with Co331 and Co285 and produced of the renowned cultivars N12, N16 and N20. N12 is the most widely planted cultivar in South Africa at the moment. Other progenies with NCo376 in their pedigree such as N17, N18, N19, N23 and N32 were also released.

Since the inception of SASRI crossing program, 54 cultivars have been released. When the sugar yield of the cultivars was plotted against year of release, a non-significant $(\mathrm{P}=0.1678)$ positive gain of 0.02 tons/ha per year was observed (Figure 2). Of significance is the presence of five genotypes released in the last 15 years that have broken the 15 tons/ha yield barrier indicating the potential to further attain larger gains. These five varieties are N25, N31, N44, N48 and N50 and have produced consistently very high yields in commercial plantings. The significant gains observed in the advanced stages also indicated the potential to sustain further gains in future.

\section{Future Prospects}

To enhance to the opportunity of increasing genetic gains of the SASRI breeding programs, a dedicated introgression program was established. Interest in utilisation of wild germplasm resurfaced across sugar cane breeding programs worldwide in 2000 when dissection of genome composition became possible using molecular marker and cytological technologies. The quantification of the extent of narrow genetic diversity among breeding populations [18] has also increased the need to utilise wild germplasm using introgression. In order to save time, collaborations were sought with organisations having good collections of wild germplasm, or active introgression breeding programs. Seed of crosses with wild germplasm were imported from the basic breeding program at the United Stated Department of Agriculture (USDA), Houma, Louisiana. In addition, crosses with Saccharum germplasm were made at the CTC breeding station in Camamu, Brazil in 2001, and is being evaluated to identify genotypes to further backcross to SASRI elite germplasm. Efforts to generate F1 from SASRI spontaneum collection will continue to broaden genetic base as well increase biomass of the gene pool. The high biomass progenies will be evaluated for use in cogeneration as well as ethanol production from cellulose. Introgression and recurrent selection to develop elite germplasm for eldana resistance continues and is expected to produce elite parents.

Family selection for cane yield and sucrose content has been introduced and will be intensified across all regional breeding programs. Family selection for eldana tolerance will be introduced to enhance development of resistance to eldana borer. In sugarcane, it is established that family selection for yield is more beneficial because the trait is controlled by several additive genes $[19,20]$. Individual genotype selection will be concentrated within superior families. The data used for family evaluation will be used to estimate the breeding values of the parents [21]. At the same time, the evaluation of parents will be used to build a core germplasm population of parents that are known to produce superior progenies. Other important traits such as eldana, smut and rust resistance will also be evaluated for family effects as well as breeding values of parents. It is envisaged that a parallel family evaluation programme across all the regions would eventually form the basis of the regional breeding programs. Using this approach, all crosses will be evaluated at this stage and only elite families will be planted in large numbers in the early selection stages.

Exploration and exploitation of selection models in early (non-replicated) selection stages will enhance identification of superior genotypes [22]. Selection models using logistic regression are used to predict the trait combinations, particularly for yield and quality that prevail in our selection populations. Yield components such as number of stalks, stalk diameter and stalk height are used to model cane yield in these populations [23]. This approach is expected to complement family selection in providing a mechanism to study within family population variability for yield and yield components. It is envisaged that the optimum trait combinations that impart yield advantage in different agro-climatic regions, if they exist, will be identified and could then be used as a guide during the selection process.

In summary, SASRI was established to develop sugarcane varieties after imported genotypes succumbed to diseases and were not adapted to local growing conditions. Popular sugarcane varieties released from SASRI include NCo310 and NCo376. These varieties were grown in several countries in the world where in some countries they were responsible for economic survival of sugar industries. The establishment of flowering facilities 
led to crosses being generated at SASRI. More than 60 varieties were released from these efforts and some of these varieties are popular in South Africa and other African countries. Realised selection gains for the irrigated, coastal long cycle and midlands breeding programs continue to show increasing trends. These trends indicate that potential high genetic gains among released varieties can be expected in the future. The future of SASRI breeding programs will be enhanced by increased introgression crosses to develop new and better germplasm for use in crossing. Family evaluation aimed at identifying superior selection populations will increase genetic gains. Data from family selection will be used to evaluate breeding values of parents in the SASRI gene pool. Selection models are being developed for use in optimizing selection in early stages as well as increasing the understanding of the populations in the breeding programs.

\section{Acknowledgements}

The work was supported by funding from South African Sugarcane research Institute. Former SASRI plant breeders (Peter Brett, Roger Bond, Karl Nuss, Mike Butterfield and Roy Parfitt) contributed to the successes outlined in this paper.

\section{REFERENCES}

[1] K. J. Nuss, "Plant Breeding, Crossing and Selection Programmes," South African Sugarcane Research Institute Durban, 2005.

[2] M. M. Zhou, "Sugarcane Selection: 1976-1996: Results and Procedures Used over Twenty Years of Sugarcane Selection," Information Bulletin Number 1/96, Zimbabwe Sugar Association Experiment Station, Chiredzi, 1996.

[3] P. G. C. Brett, "A Possible Method for Increasing Pollen Fertility of Sugarcane in Natal," Report of 45th Annual Meeting of the South African Association for the Advancement of Science, Oudtshoorn, 30 June-4 July 1947.

[4] K. J. Nuss, "The Contribution of Variety NCo376 to Sugar Production in South Africa from 1955 to 2000 and Its Value as a Parent in the Breeding Programme," Proceeding of the South African Sugarcane Technology Association, Vol. 75, 2001, pp. 154-158.

[5] P. G. C. Brett, "Flowering and Pollen Fertility in Relation to Sugarcane Breeding in Natal," Proceedings of the International Society of Sugar Cane Technologists, Vol. 7, 1951, pp. 43-56.

[6] R. S. Bond, "Variety of the Future," Proceedings of the South African Sugarcane Technologists Association, Vol. 69, 1995, pp. 225-226.

[7] M. K. Butterfield, "Plant Breeding Strategies for the Future," Proceedings of the South African Sugarcane Technologists Association, Vol. 69, 1995, pp. 219-220.

[8] M. K. Butterfield and K. J. Nuss, "Prospects for New Varieties in the Medium to Long Term: The Effects of
Current and Future Breeding Strategy on Variety Characteristics," South African Sugar Industry Agronomists Association, Kwa-Shukela, 2002, pp. 41-48.

[9] B. M. Shoonees-Muir, M. A. Ronaldson, G. Naidoo and P. M. Schorn, "SASTA Laboratory Manual Including the Official Methods," South African Sugarcane Technologists Association Publication, Durban, 2009.

[10] SAS, “SAS/STAT User's Guide, Version 9.2," SAS Institute, Cary, 2009.

[11] K. J. Nuss and P. G. C. Brett, "The Release of Variety NCo310 in 1945 and Its Impact on the Sugar Industry," Proceedings of the South African Sugarcane Technologists Association, Vol. 69, 1995, pp. 1-8.

[12] P. A. Donovan, "An Empirical Evaluation of the Sugarcane Variety NCo310," Proceedings of the South African Sugarcane Technologists Association, Vol. 70, 1996, pp. 93-102.

[13] S. C. Shih and P. Y. Juang, "The Role of NCo310 in Sugarcane Breeding in Taiwan," Proceedings of the International Society of Sugar Cane Technologists, Vol. 15, 1974 pp. 82-88.

[14] J. Matherne, "A History of Major Sugarcane Varieties," Proceedings of the International Society of Sugar Cane Technologists, Vol. 13, 1969, pp. 1061-1069.

[15] N. Rozeff, "Saying Goodbye to an Old Friend," Sugar Journal, Vol. 49, 1986, p. 24.

[16] M. M. Zhou, "Performance of Varieties N14 and NCo376 in the South East Lowveld of Zimbabwe," Proceedings of the South African Sugarcane Technologists Association, Vol. 78, 2004, pp. 153-160.

[17] D. P. Viator and M. T. Henderson, "Genetic Behaviour of Resistance in Sugarcane to the Sugarcane Borer Diatrea saccharalis (F)", Proceedings of the International Society of Sugar Cane Technologists, Vol. 13, 1971, pp. 276-285.

[18] R. Ming, P. H. Moore and K. K. Wu, "Sugarcane Improvement through Breeding and Biotechnology," Plant Breeding Review, Vol. 27, 2006, pp. 115-118.

[19] D. M. Hogarth, M. J. Braithwaite and J. C. Skinner, "Selection of Sugarcane Families in the Burdekin District," Proceedings of the Australia Society of Sugar Cane Technologists, Vol. 12, 1990, pp. 99-104

[20] C. A. Kimbeng, T. A. McRae and M. C. Cox, "Optimizing Early Generation Selection in Sugarcane Breeding," Proceedings of the International Society of Sugar Cane Technologists, Vol. 24, 2001, pp. 488-493.

[21] M. G. Balzarini, "Biometrical Models for Predicting Future Performance in Plant Breeding," Ph.D. Dissertation, Louisiana State University, Baton Rouge, 2000.

[22] D. M. Hogarth and N. Berding, "Breeding for a Better Industry: Conventional Breeding," Sugarcane International, Vol. 24, No. 2, 2006, pp. 26-31.

[23] M. M. Zhou, W. Forester, B. Khomo, J. Kupen, L. Nzimande, P. Nkwanyana and A. Walton, "Using Logistic Regression Model to Aid Selection in Non-Replicated Plots in Sugarcane," Proceedings of the South African Sugarcane Technologists Association, Vol. 85, 2012, pp 241-245. 